Rupantaran : A Multidisciplinary Journal

Vol. III : 1-9, March, 2020

ISSN : 2091-0061

Research Management Cell (RMC)

Dhankuta Multiple Campus, Dhankuta

Tribhuvan University, Nepal

\title{
Language in Use: The Illocutionary Force of a Sentence
}

\author{
Ambika Prasad Poudel ${ }^{1}$ \\ Email:poudelap@gmail.com
}

\section{Abstract}

The study and analysis of different aspects of language as an effective means of communication is the main concern of linguistics. Form, meaning, and function are some of the key aspects of language while analyzing the utterances used in communication or interaction. This article makes an attempt at examining the relationships between form, the physical appearance; and function, the illocutionary force of English sentences. This study adopted systemaic review and content analysis as the methods in which conclusions were derived by synthesizing the examples and findings found in multiple resources. The conclusions drawn in this study were that forms are straight forward while determining their meaning is obfuscatory; and the relationship between form and meaning is arbitrary. When language is in use to serve communicative needs, there is often found multiple relationship between the form of an utterance and its function, the illocutionary act.

Key Words: linguistic units, arbitrary, surface structure, functionalist, illocutionary force

\section{Introduction}

Language, a unique property of human beings, is an effective tool of communication for exchanging or sharing ideas and thoughts by means of the linguistic units such as morphemes, words, phrases, clauses, and sentences. Using language in its written mode, sentences are the largest grammatical units that are more capable of expressing a more complete unit of thoughts. These units of thoughts are capable to function the exchange of meanings or messages in the process of interaction.

A sentence may be defined as the structured string of words that fall into natural groups (Jacobs \& Rosenbaum, 1993, p. 4). This is the formal definition of sentence

1. Mr. Poudel is a Lecturer of English Education at Tribhuvan University, Dhankuta Multiple Campus, Dhankuta. 
often preferred by the structural grammarians. But when we find language/sentence as a tool of communication, it gives rise to some interesting questions such as 'how does the particular structural arrangement or the form communicate the speakers' ideas or meanings?' and, 'what type of relationship is there between the arrangement and its function in communication?'

How the particular combination of linguistic items expresses the speakers' ideas or emotion is the area of semantics, the study of meaning, that studies words/utterances up to its origin. In fact, how language was born and how it does work is still a mystery. The disputes between the naturalist (who support the view that language is governed by nature and there is natural connection between the words and their meaning) and the conventionalist (who support the view that language is governed by convention: the meaning of particular word/utterance is merely the result of custom and tradition); and analogists (who support that language is regular and systematic), and anomalists (who view that the relation between the form and meaning is not logical) are still in existence (Robins, 1991). With regard to this context, this article attempts at reviewing some scholars' ideas about how the forms of the utterances in English communicate meanings. It also aims to examine the relationships between the surface structures of English sentences and their functions in communication (i. e., the illocutionary force).

\section{Methods and Materials}

This article adopted the evidence-based approach, and the Systenmatic Review (SR) and Content Anlayais (CA) as the methods. The systematic review as a method can enable the reviewer to provide his/her decisions and conclusions through comprehensive literature searches (Tranfield, Denyer, \& Smart, 2003). Systematic reviews are a method of making sense of large bodies of information, and a means of contributing to the answers to questions about what works and what does not in the particular field of study (Petticrew \& Roberts, 2006). It is widely accepted that a synthesis of results of multiple studies often provides better information for policy and practice than the results of a single study (Littell, 2006). Different works of related literature (e. g., Halliday and Hasan, 1985; Chomsky, 2002; Robins, 1991; Wasow, Perfors, and Beaver, 2005; Jacobs \& Rosenbaum, 1993; Robins, 1967; Pintadosi, Tily, and Gibson, 2012; Aarts, \& Aarts, 1986) including books, articles, and websites have been consulted for conceptualizing, and explaining and analyzing the issues to be investgated in the study.

Likewise, content analysis that was adopted in this study is one of the most common methods to analyze the documented information in the form of texts or media, rather than observation-based field notes. According to Patton (2002, p. 453) content analysis method " is used to refer to any qualitative data reduction and sense making effort that takes a volume of qualitative material and attempts to identify core 
consistencies and meaning". Following CA methods in this study, different written examples of several English sentences used in various contexts in multiple literature were analyzed to examine the relationships between their forms and functions, and their meanings in communication. Besides, the researcher's more than two decades' personal experiences of teaching and learning English in the schools and colleges have also been incorporated in the discussion and elaboration of the ideas. The article is descriptive and explanatory in nature.

\section{Results and Discussion}

In this section, different scholar's ideas about the form and meanings of linguistic expressions in English; and the way that the forms convey meaning have been discussed giving their illustrative examples.The section also deals with the relationships of the surface structures and their purpose in communication of English sentences.

\section{Form and meaning of the expressions}

The expression of a natural language, whether spoken or written, has a certain physical shape, the form; and it also has some message/s or idea/s, the meaning. Simply, a form is understood as the physical appearance of linguistic units. It refers to the meaningful sequence of phonemes from the shortest forms such as prefixes and suffixes to the largest forms- utterances or sentences (Varshney, 1993). Thus, syllables, morphemes, words, phrases, and sentences are different types of forms. In this way, a form is found at all levels of language, and at the all levels of linguistic analysis- phonological, morphological, and syntactical level. Meaning, on the other hand, refers to the things or ideas that a form refers to. To Varshney (1993), meaning is the soul of a language. Quoting Saussure, Crystal (1985, p. 161) discusses two sides meaning- signifiant, and signifie. Signifiant is the thing which signifies (i. e., the form), whereas signifie is the thing signified (i. e., meaning).

General theories of meaning have typically been developed by philosophers rather than linguits, and it might be wondered whether they have any significance for linguists at all (Foder,1977). Truly speaking, language is entirely arbitrary that though there is necessaryily direct connection between the nature of things or ideas language deal with (i. e., the meaning), and the linguistic combination (i. e., the form), we take the meanings for granted. We say that the English word baby means very young child, but what is the nature of the connection between the physical from baby and its meaning 'very young child'? The connection is not an inevitable one such that the form baby causes a picture of very young child in the listeners' mind. The overwhelming fact is that different languages use different words to express the same meaning. We must allow for the arbitrariness of the sign to its meaning. It is therefore, natural to look to the language user for the relationship between an expression and 
that to which applies. Thus, it might be hypothesized that the word baby means what it does because its speakers are conditioned to utter it when they see a very young child, or because it is associated in their minds with an idea of a very young child, or because they have internalized convention for using it in various sentential contexts to make statements, promises, prediction etc. about very young child.

The physical form of a sentence can be determined without references to its meaning, it can be predicted solely on the basis of the physical properties of the morphemes in the sentence and certain information about the syntactic configurations into which these morphemes are combined. Halliday and Hasan (1985) stress that language cannot be disassociated or disconnected from its meaning. But the determination of the meanings in the process of communication expressed by such combination is not an easy task, if not very complex. We know that the morphemes are the smallest meaningful unit of a language, but the fact is the form-meaning correlation of a linguistic unit is not systematic, that the internal physical structure of a morpheme is irrelevant to its meaning. According to Chomsky (2002, p. 107), the system of language is not well designed for use if we think from a standard functionalist's point of view. It is because in the use of language, we find many expressions that are intelligible, but not well-formed (e.g., 'eggplant', which is not an egg); and that there are many inherent ambiguities in the expressions (e. g., Flying planes can be dangerous). Likewise, difficulties arise in finding out the meaning of the word 'table' in the expressions such as 'water table', 'table knife', 'dining table', 'table of nine', 'table of routine', and ' table an amendment'. Discussing the meaning systems of the English language, Lederer (1960) claims it (English) to be a crazy language, arguing that 'French fries' were not invented in France; and neither 'sweetbreads' are sweet, nor do we see a 'horseful carriage'(as cited in Sthapit, Basnyat, Bhattarai, \& Giri, 1994). Robins (1967, p. 28) claims, “ Meaning in language is not a single sort of relation, but it involves a set of multiple relations holding between the utterances and its parts and the relevant features and the components of the environment, both cultural and physical, involved in the existence of human societies". Thus, the relation between the form of language and its meaning in communication is not inevitable, as language is a matter of convention, we take it for granted.

Ambiguities in meaning are pervasive in language use, and these occur at all levels of linguistic analysis. The functionalist theorists argue that ambiguities cause communicative problems. They imagine that a perfect and efficient communication system should completely disambiguate meanings in such a way that the receivers need not to expend effort in inferring what the speaker intends to convey. On the contrary to this view of disambiguating meanings in language use, the authors such as Zipf(1949), and Pintadosi, Tily, and Gibson (2012) claim that an efficient communication system will necessarily be ambiguous when context is informative about meaning. To them, 
ambiguity reduces the memory demands of storing lexicon and that the speakers can minimize their effort if all meanings are expressed by simple maximally ambiguous word. Pintadosi, Tily and Gibson (2012) argue that ambiguity is a fuctional property of language that allows for greater communicative efficiency. They claim that ambiguity is a desirable property of a communication system because unambiguous meaning is partly redundant with the context, and therefore, inefficient. It is also that ambiguity allows re-use of words and sounds which are more easily perceived or understood. They argue that all efficient communication systems will be ambiguous which allows for greater ease of processing by permitting efficient linguistic units to be re-used. On the other hand, Wasow, Perfors, and Beaver (2005) claim that it is unlikely that a speaker's effort is minimized by a totally ambiguous language since confusion means that the speaker may need to spend effort clarifying what was intended. In this way, there are both positive and negative explanations about the complexity of meanings of a linguistic form or linguistic expression.

\section{Sentences and their functions in communication}

A sentence may be regarded as the highest unit of grammatical description. If we study English sentences, especially their arrangement or combination, we may find mainly four types of form - declarative $(s+v)$, interrogative $(v+s)$, imperative (verb in imperative mood), and exclamatory (how/what $+\mathrm{s}+\mathrm{v}$ !) (Aarts, \& Aarts, 1986, p. 94). This arrangement is the mechanical production of a sentence, i.e. if you combine the units of language in $\mathrm{s}+\mathrm{v}$ pattern, it produces declarative sentences and if in $\mathrm{v}+\mathrm{s}$ pattern, interrogative and so on. As in a machine, a systematic process produces similar types of goods, so does happen in producing sentence too. But this type of mechanical process may give semantically ill-formed as Chomsky pointed out colorless green ideas sleep furiously, which is described as well-formed structurally (Jacobs \& Rosenbaum, 1993). In fact, using sentences/languages is more than this; they give a sense/meaning, and are used to fulfill our intensions and desires. In the process of communication, each sentence has a particular function and that the sentences are used in various ways according to our purpose such as- greeting, requesting, persuading, advising and so on. This function in communication of a sentence is called 'illocutionary force' (Aarts, \& Aarts, 1986), which is a dimension of communicative act. Illocutionary force or illocutionary function in speech-act theory refers to a speaker's intention or the function the speaker performs. Because as any other objects, language is also used for a particular purpose or particular function; the study of sentence/language should be focused on the investigation and analysis of the illocutionary force of sentences that why, when and how they are used.

The four types of sentence forms mentioned above, (i.e. declarative, interrogative, imperative, and exclamatory) may be said to be primarily associated with one particular function in speech situation. That is to say, the declarative forms are chiefly used for 
making statements, interrogative forms for asking questions, imperative forms for giving commands, and exclamatory forms for making exclamations. This has been clearly shown in the Table 1.

Table 1: Sentence structures and their communicative functions

\begin{tabular}{|l|l|l|}
\hline \multicolumn{1}{|c|}{$\begin{array}{c}\text { Grammatical from/ } \\
\text { sentences structure }\end{array}$} & $\begin{array}{c}\text { Function in } \\
\text { communication/ } \\
\text { illocutionary force }\end{array}$ & \multicolumn{1}{|c|}{ Sentence/example } \\
\hline Declarative $(\mathrm{s}+\mathrm{v})$ & Making statements & He lives in Dhankuta. \\
\hline Interrogative $(\mathrm{v}+\mathrm{s})$ & Asking question & What does she write? \\
\hline $\begin{array}{l}\text { Imperative } \\
(\mathrm{v} \text { in imperative mood) }\end{array}$ & Giving command & Shut the door. \\
\hline Exclamatory (what/how $+\mathrm{s}+\mathrm{v} !)$ & Making exclamation & What a clever girl she is! \\
\hline
\end{tabular}

However, a form of a sentence is not sufficient on its own to account for how it is used as a means of communication. Therefore, the illocutionary force a sentence contains should be determined not in isolation, or simply by studying the grammatical structure, but also the purpose for which it is used. Because the same string of words may be uttered on different occasion with quite different intention and effects, determination of language function can successfully be done only if we take into account the whole context or situation, speaker, hearer etc. The point is that, the same form may serve various illocutionary forces depending on the context and the intention of the speaker. For example, the sentence why don't you read the book? has an interrogative form unambiguously but its illocutionary force is ambiguous. Depending on the context or situation, it may exhibit several illocutionary forces such as-asking question (when the speaker wishes to know why somebody never read the book), giving command (when the speaker tells the hearer to do so). It could also be interpreted as a suggestion or a complaint. This multiple relation between form and function has been illustrated in Table 2 .

Table 2: Form and functions of sentences

\begin{tabular}{|c|l|l|}
\hline Form & Sentence/example & \multicolumn{1}{c|}{ Function/Illocutionary force } \\
\hline \multirow{5}{*}{ Interrogative } & \multirow{4}{*}{$\begin{array}{l}\text { Why don't you close } \\
\text { the window? }\end{array}$} & $\begin{array}{l}\text { Asking question (when the speaker wants to } \\
\text { know why the window is open) }\end{array}$ \\
\cline { 3 - 3 } & $\begin{array}{l}\text { Giving suggestion (when the speaker wants } \\
\text { to provide an advice to close the window) }\end{array}$ \\
\cline { 3 - 4 } & $\begin{array}{l}\text { Making a complaint (when the speaker } \\
\text { complains about the opening of the window) }\end{array}$ \\
\cline { 3 - 3 } & $\begin{array}{l}\text { Giving an order (when the speaker wants the } \\
\text { receiver to close the window) }\end{array}$ \\
\hline
\end{tabular}


Likewise, the same illocutionary force can be expressed by means of several forms. For example, the sentences Try the fried potatoes and Come around on Saturday both have the same form, i.e, imperative, but they have different illocutionary forces giving suggestion and invitation respectively. In the same way, the same illocutionary force giving command can be expressed by grammatical forms as shown in the Table 3.

Table 3: Form-function relations

\begin{tabular}{|l|l|l|}
\hline Illocutionary force & \multicolumn{1}{|c|}{ Sentence/example } & Grammatical form \\
\hline \multirow{3}{*}{ Giving command } & What are you laughing at? & Interrogative \\
\cline { 2 - 3 } & Shut up & Imperative \\
\cline { 2 - 3 } & You will open your book at once. & Declarative \\
\hline
\end{tabular}

To be brief, whereas the sentence's form is stable and straightforward, its illocutionary force is variable and depends on specific situational and social factors. A form or surface structure can be used to carry out more than one type of illocutionary act, and a pragmatic function can be carried out by more than one surface structure type (Akmajian, 1984). In other words, there is no one-to-one correlationship between the grammatical form of a sentence and its function in communication. The same form may have various illocutionary forces and that the same illocutionary force can be expressed by several forms. This is best illustrated in Table 4 .

Table 4: Multiple relation between form and function

\begin{tabular}{|c|c|c|}
\hline $\begin{array}{l}\text { Grammatical } \\
\text { form }\end{array}$ & Illocutionary force & Example/sentences \\
\hline Declarative & $\begin{array}{l}\text { 1. Making statements } \\
\text { 2. Warning. } \\
\text { 3. Giving command } \\
\text { 4. Requesting. }\end{array}$ & $\begin{array}{l}\text { 1. I will buy a car. } \\
\text { 2. You are treading on thin ice, Mister. } \\
\text { 3. will open your book at once. } \\
\text { 4. I would like to listen to the news. }\end{array}$ \\
\hline Interrogative & $\begin{array}{l}\text { 1. Requesting } \\
\text { 2. Asking question } \\
\text { 3. Making exclamation } \\
\text { 4. Giving command }\end{array}$ & $\begin{array}{l}\text { 1. Would you mind explaining about this? } \\
\text { 2. What is the title of the story? } \\
\text { 3. Isn't this wonderful? } \\
\text { 4. What are you looking at? }\end{array}$ \\
\hline Imperative & $\begin{array}{l}\text { 1. Wishing } \\
\text { 2. Inviting } \\
\text { 3. Warning } \\
\text { 4. Giving command }\end{array}$ & $\begin{array}{l}\text { 1. Have a good weekend } \\
\text { 2. Come on and join us. } \\
\text { 3. Be careful with that gun. } \\
\text { 4. Be quiet. }\end{array}$ \\
\hline Exclamatory & $\begin{array}{l}\text { 1. Requesting } \\
\text { 2. Making exclamation }\end{array}$ & $\begin{array}{l}\text { 1. What tasty apples these are! } \\
\text { 2. What a clever the boy is! }\end{array}$ \\
\hline
\end{tabular}




\section{Conclusion}

On the whole, though we spend a lot of time on the study of basic English grammar and have a good knowledge of everyday English vocabulary, we may find that a knowledge of grammar and vocabulary is not enough to be an effective speaker of English in real world. It is essential to learn how to use language and how to do things with language. In other words, we should learn how to persuade, request, forgive, advice and so on; or to do things whatever we want by means of language. For this, we must learn not only the application of the grammatical rules of a language in order to from grammatically correct sentences but also to use those sentences appropriately in various speech situations. And, this is acquiring communicative competence, the cry of the day.

To conclude, language grammar and language use are the different conventional systems of a language. Language grammar is mainly concerned with the correctness or accuracy aspect of language whereas language use is concerned with the communicative skills or communicative competence, the appropriate and contextual use of language. Though we spend lots of time on studying the grammatical features of a language, we need to give more emphasis to learn and understand the illocutionary force of sentences to be more familiar with language in use.

\section{References}

Aarts, F. \& Aarts, J. (1986). English syntatic Structure: Pergamon Press: New York.

Akmajian, A. (1984). Sentence types and the form-function fit. The natural language and linguistic theory 2 (1984) 1-23.0167-806X/84/0021-0001

Chomsky, N. (2002). An interview on minimalism. In A. Bellitte and L. Rizzi (Eds), On nature on language (pp. 92-161), New York: CUP.

Foder J.D. (1977). Semantics: theories of meaning in generative grammar. New York: Crowell.

Halliday, M. A. K., \& Hasan, R. (1985). Language, context, and text: aspects of language in a social-semiotic perspective. Oxford: Oxford University Press.

Jacobs, R. A. \& Rosenbaum, P. S. (1993). English transformational grammar. New Delhi: Wiley Eastern Limited.

Littell, J. H. (2006). Systematic reviews in the social sciences: A Review . Evidence \& Policy, 2(4), 535-537. doi:10.1332/ 174426406778881728

Pattom, M.Q. (2002). Qualitative Research and Evaluation Methods. New Delhi: Sage publication.

Petticrew, M., \& Roberts, H. (2006). Systematic review in social sciences: A practical guide. USA: Blackwell Publishing. 
Piantadosi, S. T., Tily, H. \& Gibson, E. (2012). The communicative function of ambiguity in language. www.elsevier.com/ locate/COGN. Cognition 122 (2012) 280-291

Robins, R. H. (1967). General Linguistics: an introductory survey. New York: Longman.

Robins, R. H. (1991). A short history of linguistics. New York: Longman.

Sthapit, S. K., Basnyat, S., Bhattarai, G. R., \& Giri, R. A. (1994). A course in general English. Kathmandu: Authors.

Tranfield, D., Denyer, D., \& Smart, P. (2003). Towards a methodology for developing evidence-informed management knowledge by means ofsystematic review . . British Journal of Management, 14(3), 207-222. 